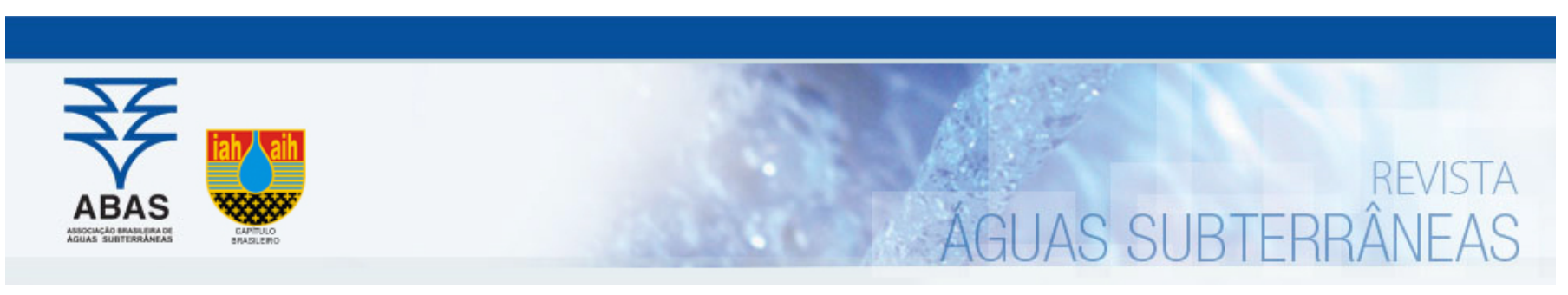

Artigos

\title{
Compartimentação hidrogeológica do Sistema Aquífero Guarani na escarpa da serra geral no nordeste do RS
}

\section{Hydrogeological compartmentation of the Guarani Aquifer System in the serra geral escarpment in the northeast of RS}

\author{
Alex Bortolon de Matos; Pedro Antonio Roehe Reginato²; Gustavo Barbosa Athayde ${ }^{2} \bowtie$ \\ 1 Universidade Federal de Roraima (UFRR) / Universidade Federal do Rio Grande do Sul (UFRGS), Porto Alegre, RS \\ 2 Universidade Federal do Rio Grande do Sul (UFRGS), Porto Alegre, RS
}

\section{凹alexbortolon@gmail.com, pedro.reginato@ufrgs.br, gustavo.athayde@ufrgs.br}

\section{Resumo}

Palvras-chave:

Sistema Aquífero Guarani.

Compartimentação.

Modelo Hidrogeológico.

\begin{abstract}
O objetivo deste trabalho foi avaliar a compartimentação do Sistema Aquífero Guarani (SAG), na Escarpa da Serra Geral no nordeste do RS. Para tanto, foram utilizadas informações de 276 poços tubulares e os traçados de lineamentos morfoestruturais em diferentes escalas, visando, com isso, promover a delimitação de compartimentos hidrogeológicos e avaliar a sua influência nas características do aquífero. Os resultados foram empregados na elaboração de um modelo hidrogeológico conceitual. Foi observado que as variações na cota do topo do SAG apresentam relações com o relevo da região. 0 fluxo de água subterrânea segue das regiões mais altas em direção aos limites dos compartimentos, acompanhando, em geral, o topo do SAG, com características de um aquífero livre. A capacidade específica apresentou uma grande variação entre os compartimentos, com os poços mais produtivos localizados próximo das áreas de descarga do aquífero. Com relação à hidroquímica, verificou-se pouca diferenciação entre as águas, com as variações ocorrendo principalmente por influência das características locais. Dessa forma, os resultados obtidos nesse estudo demonstram que nessa região o SAG se apresenta compartimentado, e que essa compartimentação tem influência tanto na produtividade, quanto na cota do topo do SAG e no fluxo da água subterrânea.
\end{abstract}

Abstract

The objective of this work was to evaluate the compartmentation of the Guarani Aquifer System (GAS) in the Serra Geral escarpment in the northeast of the RS. Therefore, the information of 276 tubular wells and the trace of morphostructural lineament at different scales were used, aiming to promote the delimitation of hydrogeological compartments and to evaluate their influence on the aquifer characteristics. The results were used in the elaboration of a conceptual hydrogeological model. It was observed that the variations of the top of the GAS present relations with the relief of the region. The groundwater flow follows from the highest regions towards the limits of the compartments, following, in general, the top of the GAS, with characteristics of unconfined aquifer. The specific capacity presented a great variation between the compartments, with the most productive wells located near the discharge areas of the aquifer. Regarding the hydrochemistry, it was verified little differentiation between waters, with variations occurring mainly due to the influence of local characteristics. Thus, the results obtained in this study demonstrate that, in the study area, the GAS is compartmentalized, and that this compartmentation has influence both in productivity, as well as in the top of the SAG and in the groundwater flow.

DOI: http://dx.doi.org/10.14295/ras.v32i1.28965

\section{INTRODUÇÃO}

As limitações impostas na utilização das águas superficiais, seja por conta da sua escassez ou contaminação, tem proporcionado nos últimos anos um aumento na utilização das águas subterrâneas, muitas vezes, sem um devido planejamento.

Nesse contexto, existe a necessidade de se compreender a dinâmica e o funcionamento dos aquíferos onde essas águas se encon- tram armazenadas, com o intuito de proporcionar sua utilização de maneira racional, evitando problemas futuros.

No nordeste do Rio Grande do Sul, encontram-se dois grandes sistemas aquíferos, o Guarani (SAG) e o Serra Geral (SASG). O SAG é caracterizado por aquíferos granulares, variando de livre à confinado, que ocorrem associados a rochas sedimentares pertencentes a diferentes formações geológicas, com destaque nessa região para os arenitos eólicos da Formação Botucatu. Já o SASG é composto 
por aquíferos fraturados que ocorrem associados às estruturas tectônicas e de resfriamento das rochas vulcânicas da Formação Serra Geral (REGINATO, 2003; MACHADO, 2005).

A área em estudo encontra-se na região geomorfológica da Escarpa da Serra Geral, localizada entre o Planalto dos Campos Gerais e a Depressão Central Gaúcha, possuindo variações significativas de amplitude do relevo. Por essa ser uma região de transição entre o SAG confinado e a área de afloramento, é comum a existência de intercalações de áreas com e sem a presença das rochas vulcânicas sobrepondo os arenitos da Formação Botucatu, sendo esses locais sem a cobertura, segundo Santos et al. (2007), mais propícios à recarga direta do aquífero.

A presença de lineamentos, mapeados na região em diferentes escalas por Machado (2005), Betiollo (2006) e Soares et al. (2007), demonstra a importância que essas estruturas podem ter na delimitação de compartimentos, bem como na influência das características físicas e hidroquímicas.
Em função dessa heterogeneidade do SAG, os estudos da compartimentação em pequena escala, como os desenvolvidos por Araújo et al. (1999), para a região do Mercosul, e por Machado e Freitas (2005), para todo o Rio Grande do Sul, não conseguem representar em detalhes a dinâmica do SAG na área de estudo. Por outro lado, estudos em grandes escalas apresentam um foco apenas em características locais, como em Ivoti (HEINE, 2008), Santa Maria (GIARDIN e FACCINI, 2004), e Estrela (GIARDIN e FACCINI, 2011).

Com isso, este trabalho busca avaliar a compartimentação do SAG na região da Escarpa da Serra Geral do nordeste do RS, e sua influência nas características do aquífero, como fluxo de água subterrânea, hidroquímica, produtividade e cota do topo do SAG.

\section{MATERIAIS E MÉTODOS}

A área de estudo compreende parte da Escarpa da Serra Geral, na região nordeste do RS, localizada entre as coordenadas UTM sul 6754819 e 6706744 , e UTM leste 385298 e 524874 (Figura 1).

Figura 1 - Localização da área de estudo

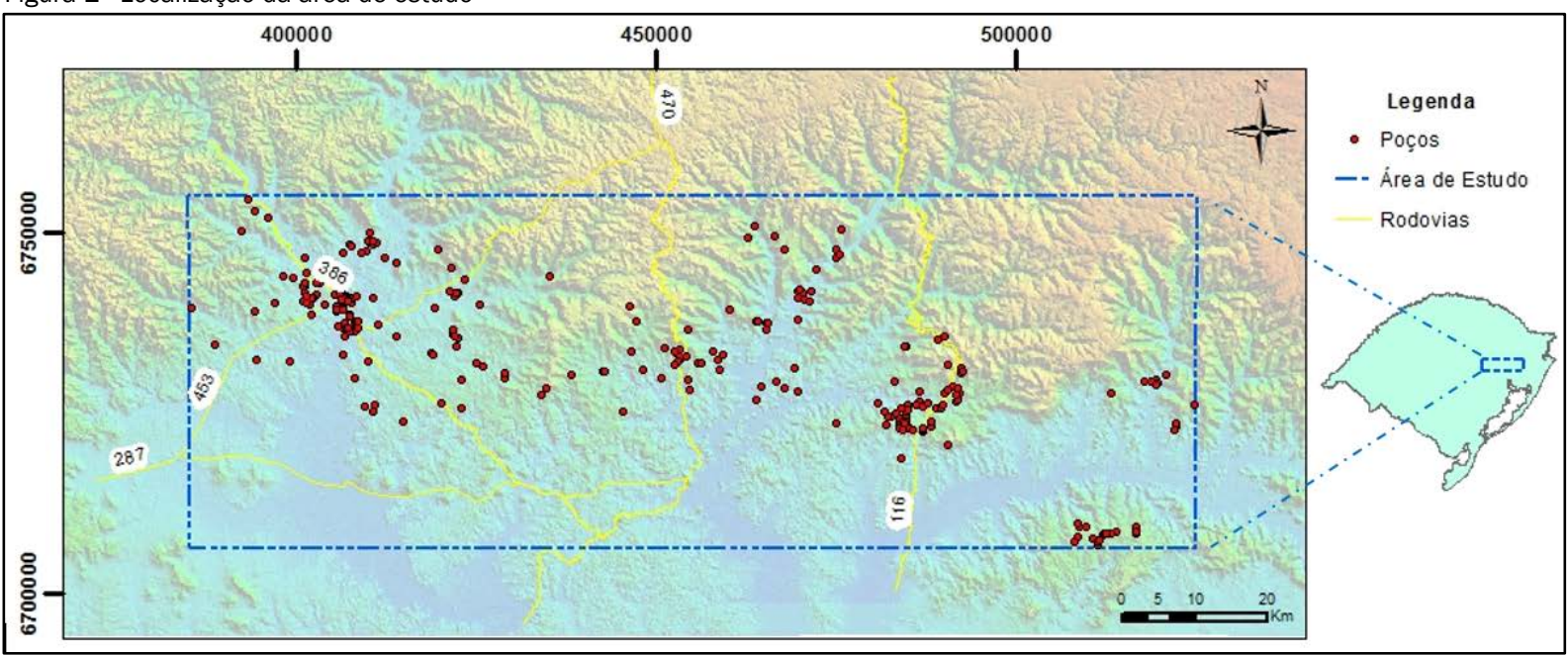

Nessa área, verificou-se a existência de 345 poços tubulares, dos quais foram selecionados 276 poços que continham perfil geológico e construtivo, de modo que se pudesse avaliar a ocorrência das rochas sedimentares e vulcânicas.

Estes dados foram obtidos a partir de diversas plataformas, como o Sistema de Informações de Águas Subterrâneas (SIAGAS), da Companhia de Pesquisa de Recursos Minerais (CPRM), relatórios da CORSAN (Companhia Riograndense de Saneamento), e relatórios de perfuração e de análises químicas de empresas particulares.

A metodologia aplicada no desenvolvimento desse estudo, apresentada no fluxograma da Figura 2, teve como premissa a utilização das informações químicas, físicas e estruturais dos sistemas aquíferos existentes na região para a delimitação de compartimentos hidrogeológicos e a sua caracterização.

Para tanto, a informação do contato entre as rochas vulcânicas e sedimentares, constantes nos perfis, bem como as cotas topográficas dos locais, foram utilizadas na obtenção do posicionamento do topo do SAG. Em alguns casos, as cotas topográficas não consta- vam nos relatórios, ou suas medições ocorrendo a mais de 40 anos, com equipamentos de baixa precisão, sendo nessas situações utilizadas as cotas do SRTM (Shuttle Radar Topography Mission), de 30 $\mathrm{m}$ de resolução, de maneira similar à proposta por Demétrio et al. (2006) e Lobler et al. (2014).

Os testes de bombeamento, que constavam nos relatórios, não são uniformizados com relação ao tempo, pois estes foram executados por diferentes períodos (12h, 24h, 36h, por exemplo). Para as análises de produtividade, optou-se pela utilização dos valores de capacidade específica referentes à $24 \mathrm{~h}$, por apresentarem uma frequência maior de dados, representando um universo amostral de 127 poços.

Os relatórios de análises químicas, quando existentes, apresentaram lacunas em alguns parâmetros e elementos. Dessa forma, foram selecionados 43 relatórios que continham dados necessários para a classificação química das águas, que foi realizada a partir do módulo do diagrama de Piper do software Qualigraf 1.17 (MOBUS, 2016). 
Figura 2 - Metodologia utilizada no desenvolvimento do estudo

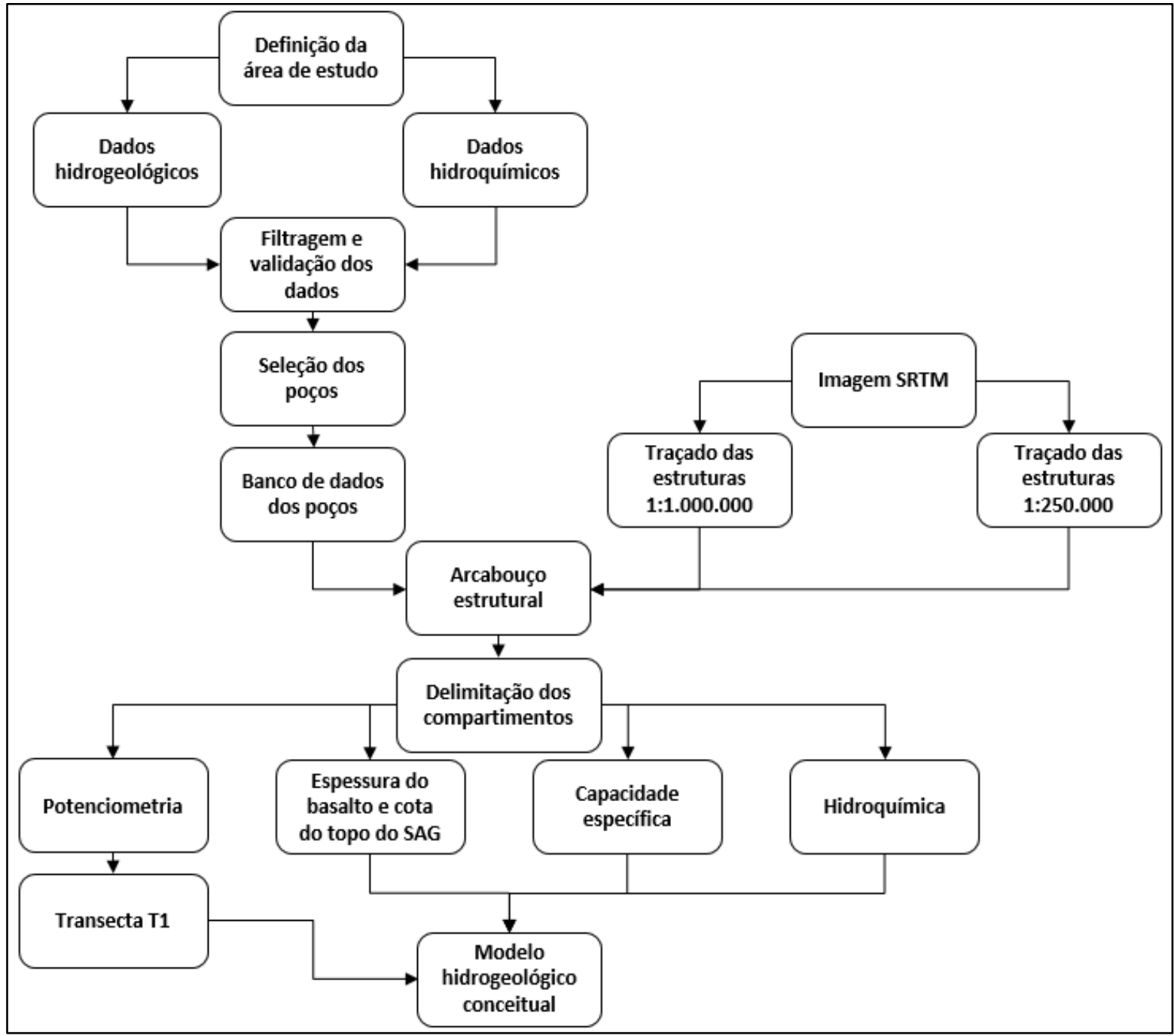

Foi utilizado como parâmetro de definição de fluxo a carga hidráulica, que foi calculada tendo como base os dados mais recentes de níveis estáticos existentes nos relatórios de 256 poços que possuím essa informação. A partir desses dados, foi utilizado o interpolador topo to raster do software ArcGIS, de modo a se obter a superfície potenciométrica da área. A validação do mapa potenciométrico foi feita a partir da análise da carga hidráulica entre conjuntos de poços e com o relevo, em uma escala de maior detalhe.

Para traçar os lineamentos morfoestruturais, utilizou-se modelos digitais de elevação, do SRTM, na escala de 1:250.000 e 1:1.000.000, obtidas a partir do software Global Mapper. 0 modelo passou por uma filtragem para que adquirisse uma falsa iluminação nas direções NW e NE, de forma a facilitar a visualização e interpretação das estruturas. Posteriormente, as imagens foram extraídas para o software ArcGIS, onde foram traçados os lineamentos.

Para a extração das informações dos lineamentos traçados foi utilizada a ferramenta AzimuthFinder, desenvolvida por Queiroz et al. (2014), que serviram de base para a elaboração dos diagramas de roseta, com o uso do software Stereonet. A partir da interpretação dos diagramas, foram feitas as análises das principais orientações das estruturas.

Para a delimitação dos compartimentos hidrogeológicos, foi utilizado como base as áreas limitadas por estruturas bem definidas, observadas em diferentes escalas. Posteriormente, foi feita uma avaliação das principais características do SAG para observar a influência da compartimentação nas suas variações, e elaborar um modelo conceitual que represente o seu comportamento.

O modelo hidrogeológico conceitual é apresentado na forma de um perfil, sendo a sua elaboração feita por meio do traçado de uma transecta (T1). A transecta tem orientação aproximada leste-oeste, proporcionando assim um corte da área de estudo, e foi definida visando acompanhar a sequência de fluxo, passando por altos e baixos potenciométricos. Nesse perfil são apresentados dados dos poços interceptados por T1, como espessura das rochas vulcânicas, cota do topo do SAG, posicionamento do nível estático, bem como o relevo da região, localização dos principais cursos d'água e os limites dos compartimentos.

\section{RESULTADOS}

\subsection{Arcabouço estrutural}

Para o mapa de lineamentos dessa região, foram traçadas 7.935 estruturas na escala 1:250.000 (Figura 3), tendo como as direções mais frequentes as Norte-Sul e Leste-Oeste, e secundariamente para os quadrantes Noroeste e Nordeste, sendo as principais orientações N00-10W, N80-90W, N30-50W e N40-60E. 
Figura 3 - Mapa de lineamentos identificados na escala 1:250.000

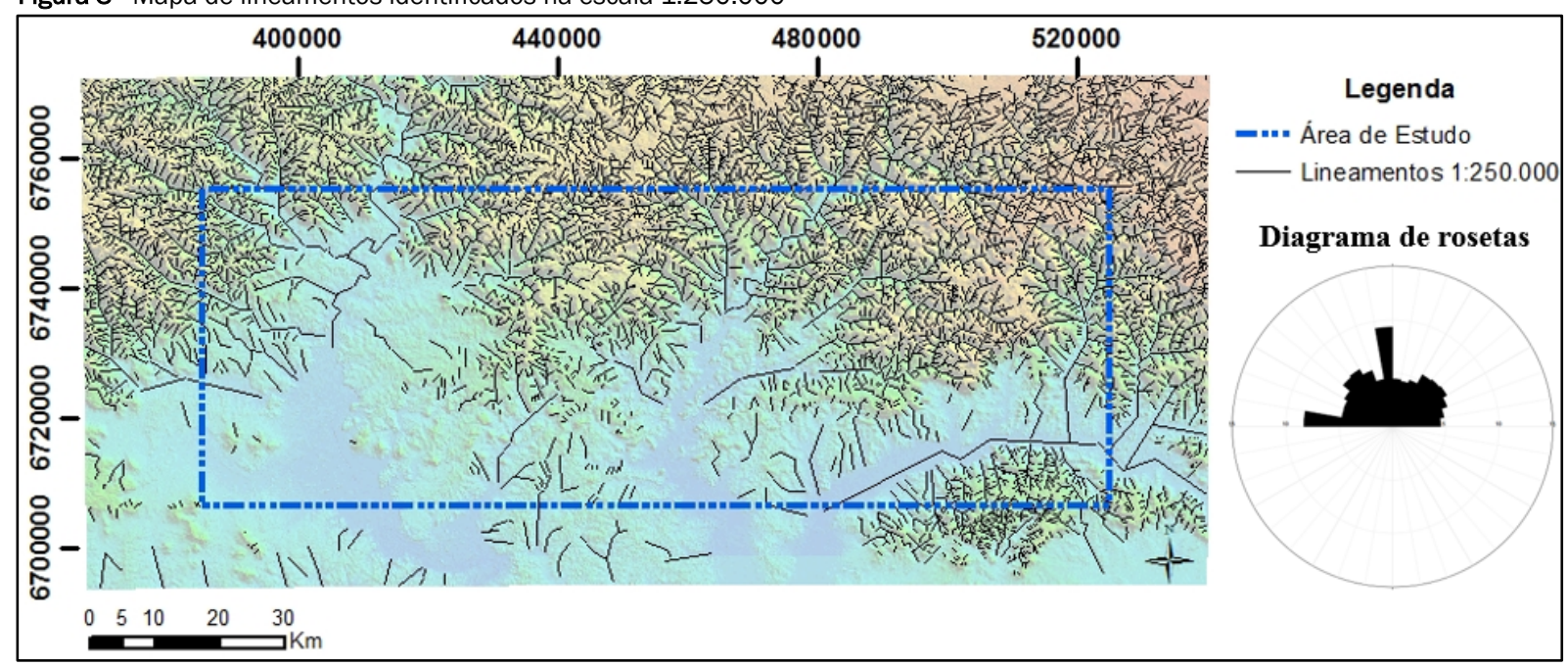

Figura 4 - Mapa de lineamentos identificados na escala 1:1.000.000

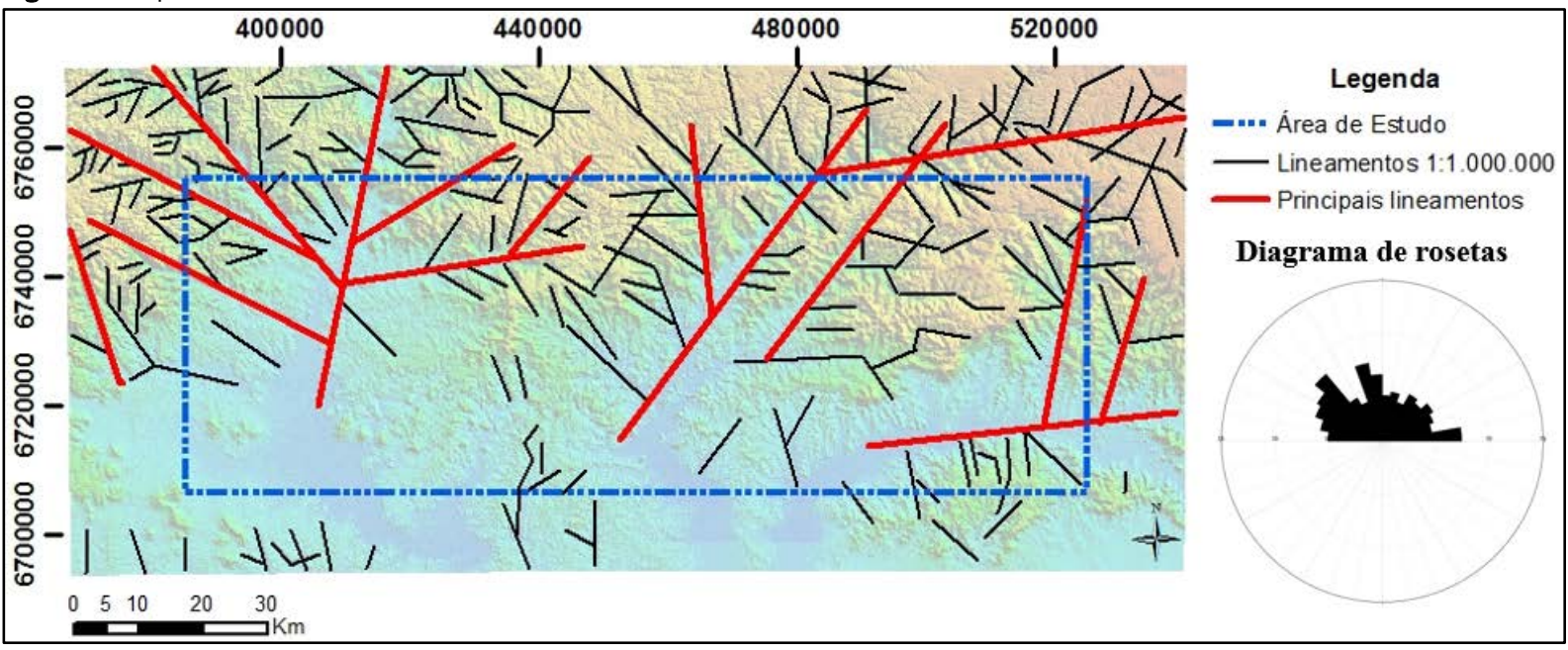

Na escala 1:1.000.000, foram traçados 257 lineamentos, com direções mais frequentes as Norte-Sul, Leste-Oeste e Noroeste, e secundariamente as Nordeste. Nessa escala, as orientações N1020W, N40-50W e N80-90E foram as principais. Vale destacar a presença de 15 lineamentos de médio porte, com comprimentos superiores a $20 \mathrm{~km}$, observados nessa escala, com direções principais Nordeste e Noroeste, além de Norte-Sul e Leste-Oeste (Figura 4).

Um dos pressupostos da análise da compartimentação era a de que existissem conjuntos de poços que fossem separados por esses li- neamentos, que continham informações hidrogeológicas suficientes para avaliar a atuação das estruturas.

Com base nessa avaliação, foram identificados três lineamentos, com mais de $50 \mathrm{~km}$ de comprimento, encaixados em vales, por onde passam grandes rios (Rio dos Sinos, o Rio Caí e o Rio Taquari), que foram utilizadas na avaliação da compartimentação. Os compartimentos formados pelo limite desses lineamentos foram denominados de CP1, CP2, CP3 e CP4 (Figura 5). 
Figura 5 - Arcabouço estrutural e delimitação dos compartimentos

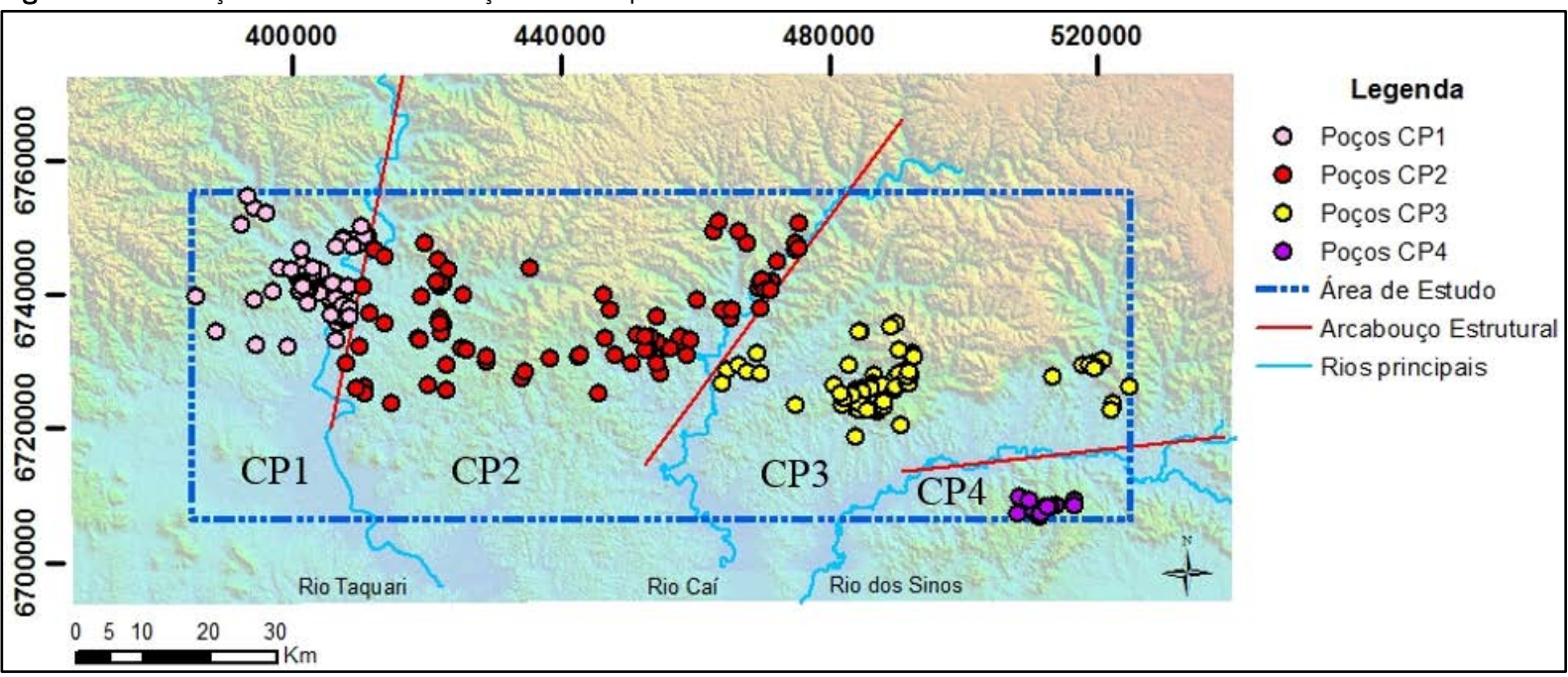

\subsection{Variação da cota do topo do SAG}

A cota do topo do SAG demonstra a existência de uma grande heterogeneidade, tanto na avaliação da região como um todo, quanto em cada compartimento (Figura 6). A Tabela 1 apresenta um resumo dessas características.

Essas informações demonstram uma distinção entre os compartimentos, além de uma grande amplitude entre as cotas máximas e mínimas, com as médias e medianas apresentando valores muito próximos. Ao relacionar cota do topo do SAG com a altimetria da região (Figura 7), verifica-se que existe uma tendência do topo do SAG de acompanhar o relevo, o que pode explicar essa grande variação encontrada dentro dos compartimentos.

Tabela 1 - Características da cota do topo do SAG, em metros

\begin{tabular}{ccccc}
\hline & CP1 & CP2 & CP3 & CP4 \\
\hline Máxima & 69 & 220 & 207 & 250 \\
Mediana & -22 & 21 & 68 & 193 \\
Média & $-23,33$ & 16,50 & 67,15 & 185,12 \\
Mínima & -132 & -117 & -108 & 98 \\
\hline
\end{tabular}

Figura 6 - Cota do topo do SAG na região

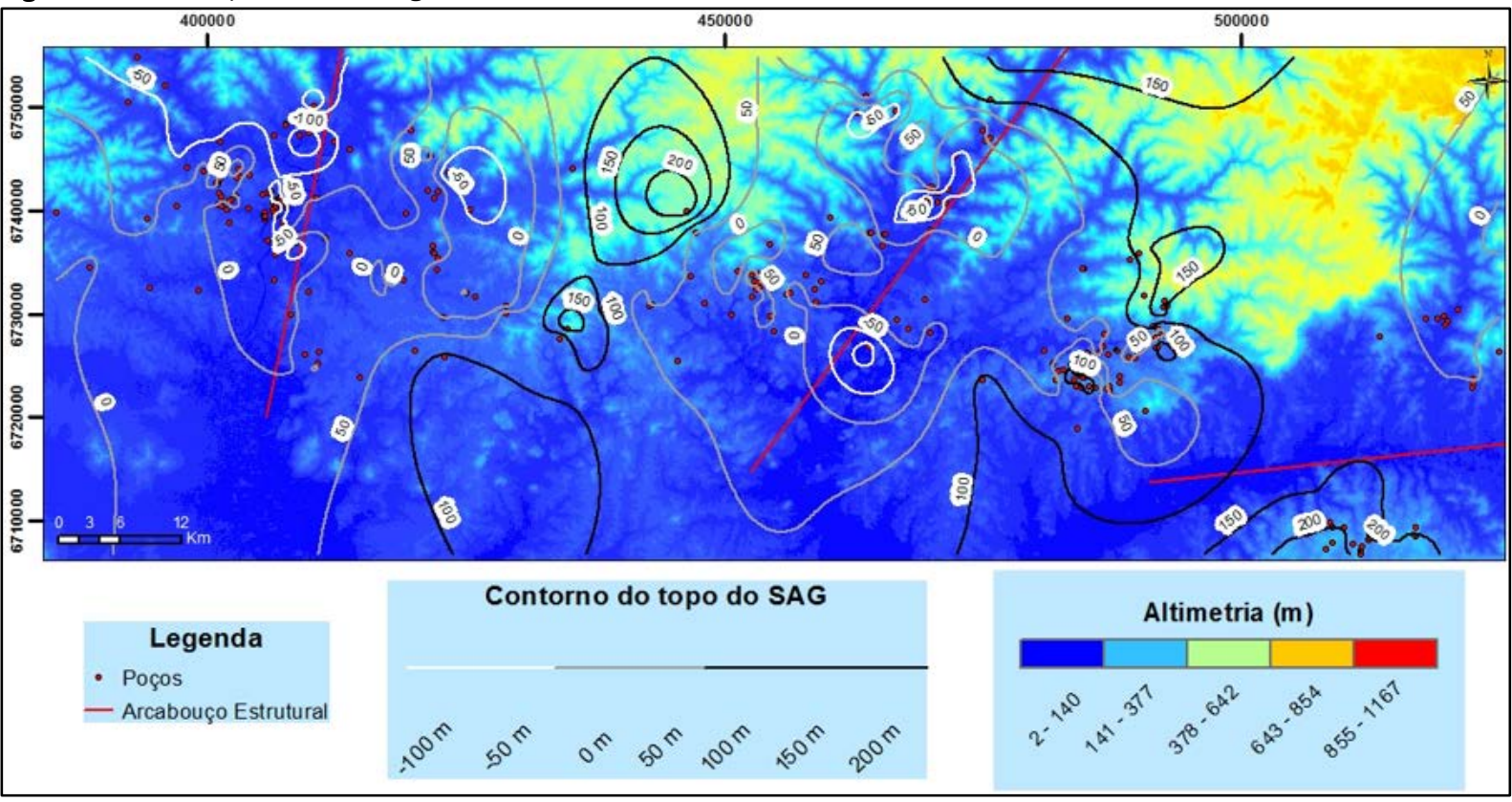




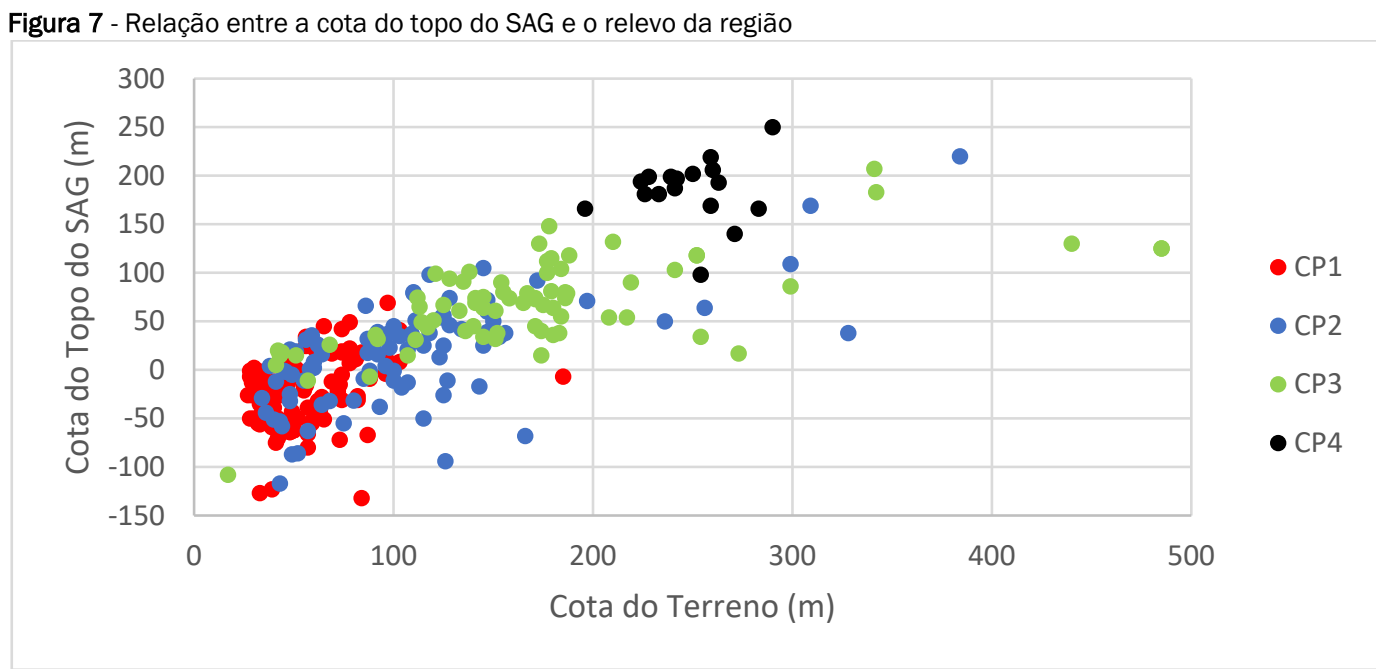

Algumas discrepâncias encontradas nessa tendência se localizam principalmente nos vales, onde foram identificados casos com variações de até $50 \mathrm{~m}$ na cota do topo do SAG entre poços, em uma pequena distância, próxima de 500 m. Como não foi observado nenhum indicativo de possível estrutura entre esses poços, uma possibilidade é que essa variação seja decorrente das variações da paleosuperfície da Formação Botucatu, visto que, segundo Scherer (2000), as paleodunas podiam chegar a até $100 \mathrm{~m}$.

Verificou-se também que, com exceção de 3 poços, no compartimento CP3 eles se encontram acima da cota $0 \mathrm{~m}$. 0 mesmo ocorre no $\mathrm{CP} 4$, só que em maior grau, com cotas superiores à 90 m. Já no CP1 e CP2 as cotas apresentam uma grande variação, desde valores bem baixos até alguns dos mais elevados da região, com a diferença de que no primeiro, $75 \%$ das cotas encontradas são negativas, enquanto que no segundo, a grande maioria das cotas são positivas. Isso demostra a existência de uma diferenciação dessa característica nos compartimentos.
Da mesma forma que o topo do SAG, as espessuras dos pacotes de rochas vulcânicas na região também apresentam grande variação. As espessuras médias se encontram próximas dos $80 \mathrm{~m}$ (entre 20 m e 360 m), o que, em geral, segundo Hindi (2007), proporciona um baixo grau de confinamento ao SAG.

\subsection{Relação do fluxo de água subterrânea com a compartimen- tação}

A partir da carga hidráulica, foi possivel definir a superfície potenciométrica para a região (Figura 8). Foram encontrados alguns altos potenciométricos, com destaque para o que se localiza na porção central da área, com níveis potenciométricos de mais de $300 \mathrm{~m}$, além de outro à nordeste, com níveis superiores a 250 $\mathrm{m}$.

Figura 8 - Mapa de superfície potenciométrica

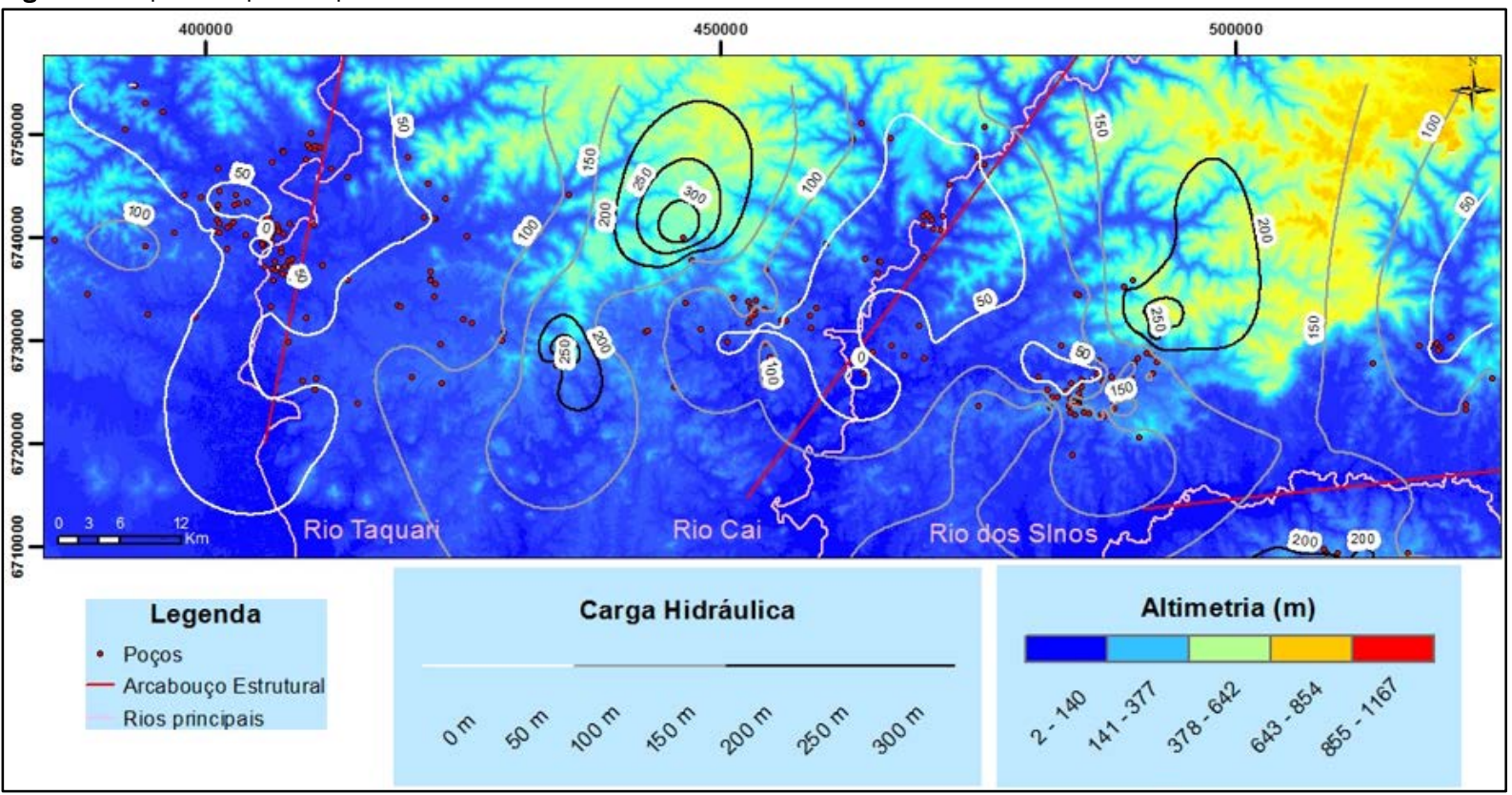


Com relação às cargas hidráulicas mais baixas, destaca-se o fato de que estas se localizam principalmente nos vales dos rios Taquari, Cai e Sinos, onde se encontram os principais lineamentos (Figura 8).

$\mathrm{Na}$ área de estudo, o nível estático possui uma tendência de acompanhar a cota do topo do SAG, que por sua vez se relaciona com o relevo, isso ocorrendo tanto regionalmente, quanto, em menor grau, em cada compartimento (Figura 9).

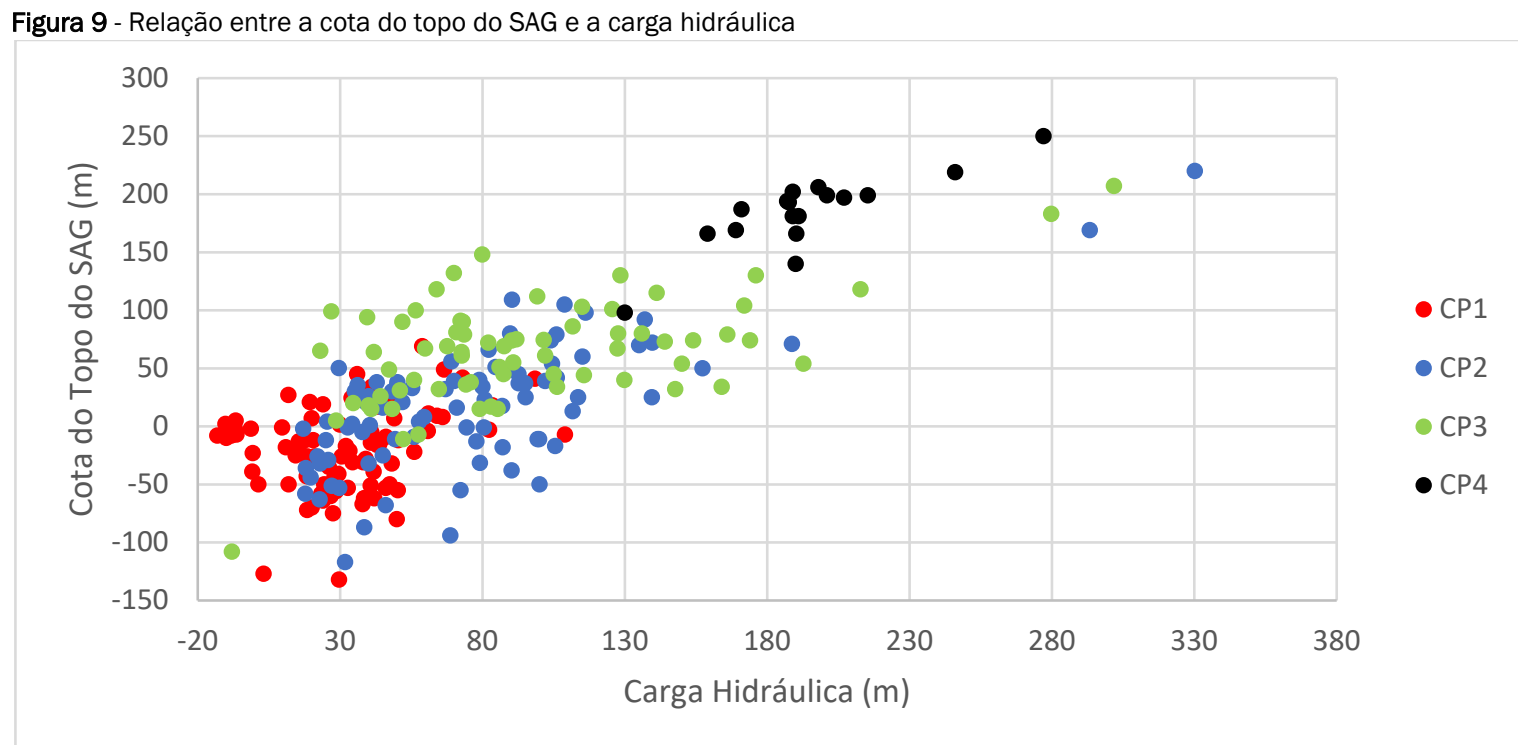

Dessa forma, o fluxo de água subterrânea tende a seguir dos altos potenciométricos que, em geral, coincidem com as maiores altimetrias da região, em direção aos rios Taquari, Cai e Sinos, nas bordas dos compartimentos, que funcionam com grandes áreas de descarga.

Levando em consideração as principais bacias hidrográficas da região em estudo (Taquari, Caí e Sinos), foi observado que as bor- das dessas bacias estão posicionadas muito próximas aos altos potenciométricos, indicando um comportamento similar do fluxo de água superficial e subterrâneo em direção as grandes drenagens (Figura 10). A exceção se deve ao baixo potenciométrico encontrado na região sudeste entre as bacias do Rio Cai e Rio dos Sinos, onde foi realizado um trabalho em escala de detalhe por Heine (2008), que identificou a ocorrência de superexplotação, o que pode estar refletindo nesses valores mais baixos.

Figura 10 - Relação entre as bacias hidrográficas e a superfície potenciométrica

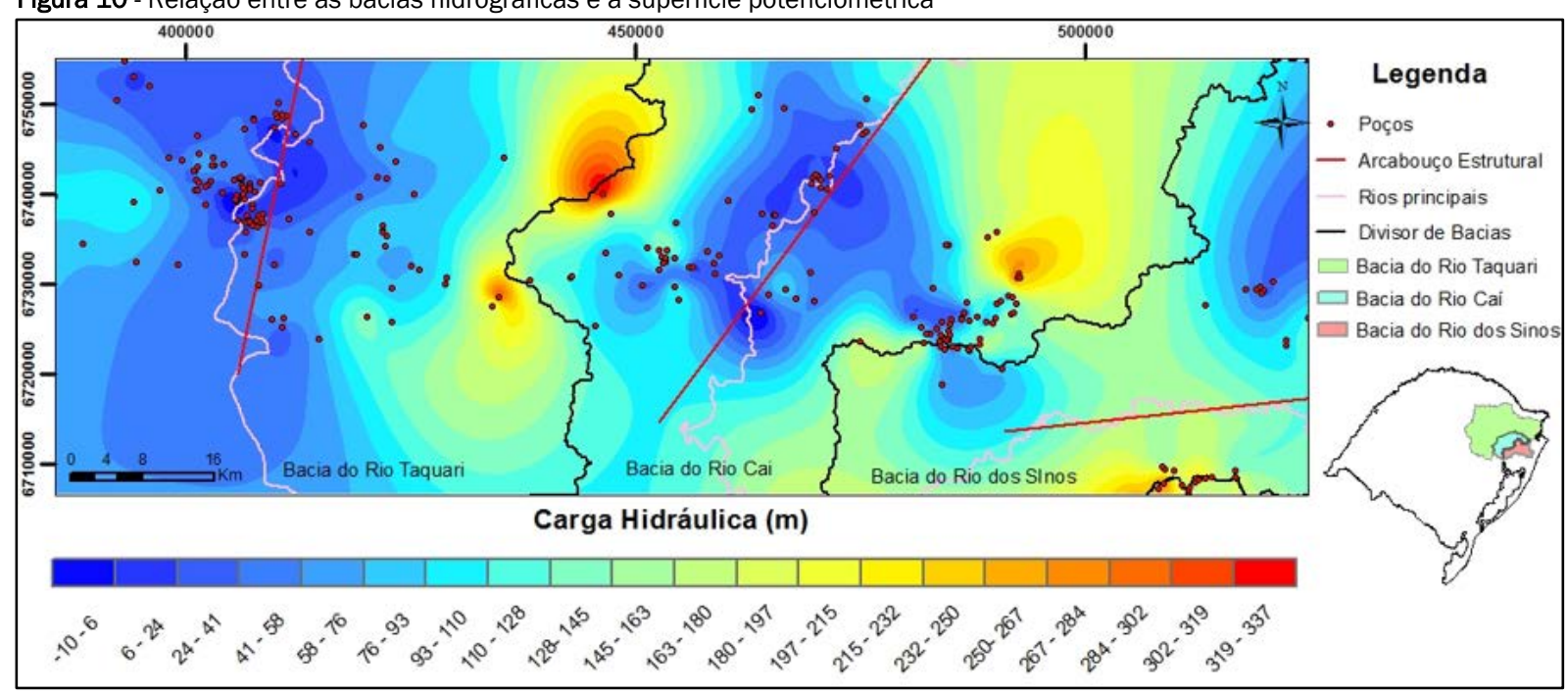

\subsection{Relação da produtividade com a compartimentação}

As capacidades específicas são menores que $1 \mathrm{~m} 3 / \mathrm{h} / \mathrm{m}$ em $56 \%$ dos poços analisados, localizados principalmente nos compartimentos CP3 e CP4, onde $60 \%$ das vazões estão abaixo do primeiro quartil $\left(0,25 \mathrm{~m}^{3} / \mathrm{h} / \mathrm{m}\right)$. Com exceção de um poço encontrado em
CP3, todos os demais com valores acima do terceiro quartil $(1,65$ $\mathrm{m}^{3} / \mathrm{h} / \mathrm{m}$ ), estão localizados em CP1 e CP2, com presença de vazões superiores à $4 \mathrm{~m}^{3} / \mathrm{h} / \mathrm{m}$, chegando a até $9,73 \mathrm{~m}^{3} / \mathrm{h} / \mathrm{m}$. A Tabela 2 apresenta os valores máximos, médios, mínimos e medianos encontrados nos compartimentos. 
Tabela 2 - Valores máximos, médios, mínimos e mediana das produtividades, em $\mathrm{m}^{3} / \mathrm{h} / \mathrm{m}$

\begin{tabular}{lcccc}
\hline & CP1 & CP2 & CP3 & CP4 \\
\hline Máximo & 9,73 & 7,66 & 1,95 & 0,25 \\
Médio & 1,77 & 1,42 & 0,42 & 0,20 \\
Mediana & 1,32 & 0,67 & 0,23 & 0,20 \\
Mínimo & 0,04 & 0,11 & 0,01 & 0,15 \\
\hline
\end{tabular}

Foi verificado também que, ao relacionar a produtividade com a carga hidráulica (Figura 11), os maiores valores foram encontrados próximos da faixa que varia entre $0 \mathrm{~m}$ e $50 \mathrm{~m}$, que corresponde ao nível de base de saturação do aquífero. Os poços onde foram em- contrados esses valores mais elevados estão localizados principalmente nas áreas próximas das grandes estruturas, onde são descarregadas boa parte do fluxo de água subterrânea da região.

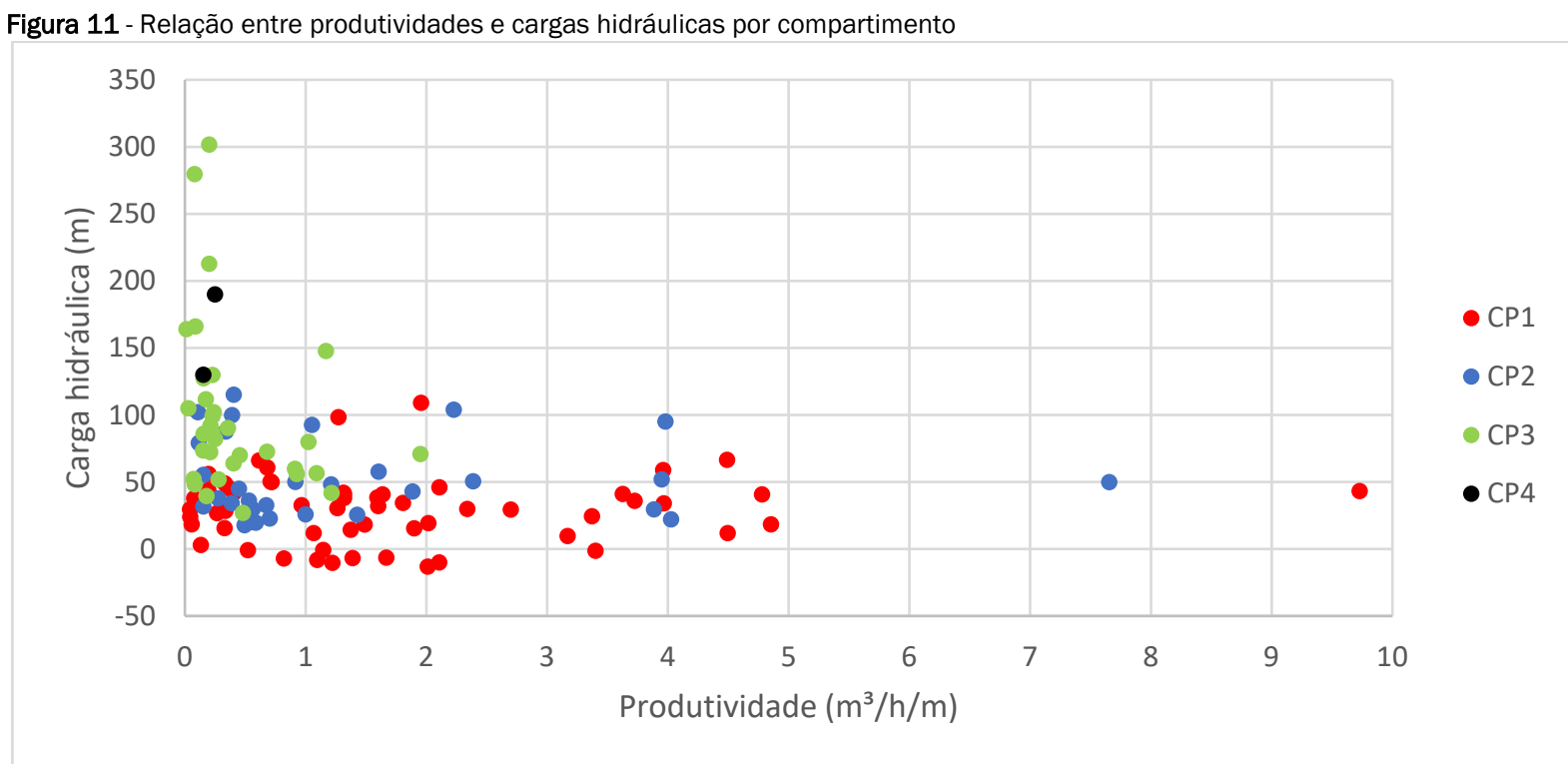

\subsection{Relação da hidroquímica com a compartimentação}

Com base nos dados hidroquímicos as águas foram classificadas como bicarbonatadas cálcicas (15 poços), bicarbonatadas cálcicas ou magnesianas (25 poços) e bicarbonatadas sódicas (3 poços).

Segundo Giardin e Faccini (2011), as águas bicarbonatadas cálcicas estão associadas nessa região ao aquífero Botucatu, enquanto que para Reginato et al. (2013), na região nordeste do RS, a variabilidade hidroquímica pode ter relação com o grau de confinamento, visto que os autores encontraram águas bicarbonatadas cálcicas ou magnesianas em locais com menor confinamento, e as águas bicar- bonatadas sódicas em locais com maior confinamento.

\subsection{Modelo hidrogeológico conceitual}

O modelo conceitual é representado no perfil hidrogeológico que foi elaborado a partir de T1 (Figura 12), que buscou acompanhar o fluxo de água subterrânea, seguindo entre os altos e baixos potenciométricos, passando por 17 poços selecionados, de modo a representar a região ao longo dos 4 compartimentos (Figura 13). A validação do modelo foi feita a partir da utilização de dados de outros poços, levando em consideração as cargas hidráulicas e o relevo. 
Figura 12 - Relação entre produtividades e cargas hidráulicas por compartimento

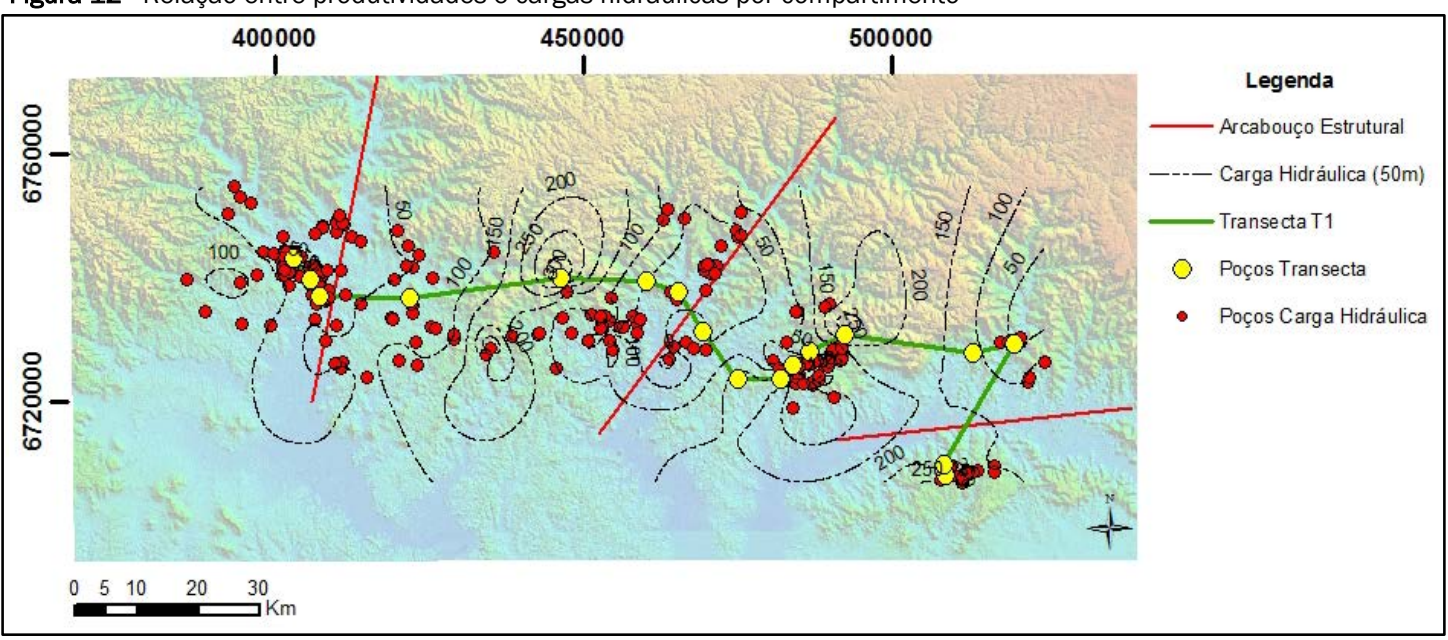

Figura 13 - Seção representativa do modelo hidrogeológico conceitual

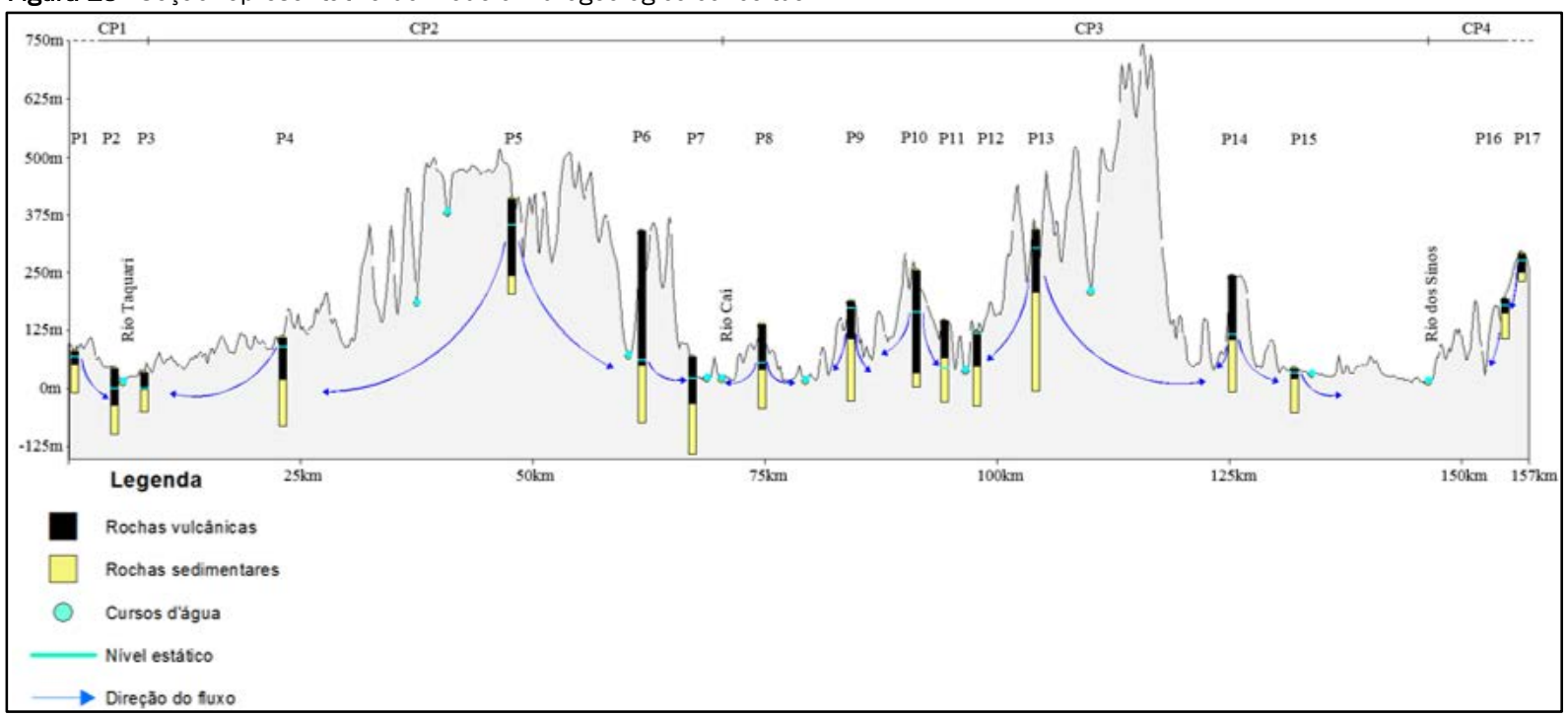

Do modelo proposto, o fluxo segue das regiões mais altas em direção aos limites dos compartimentos, acompanhando, em geral, o topo do SAG. Ao longo do caminho, são encontradas várias quebras de relevo, algumas com grandes amplitudes, além da presença de alguns rios de pequeno porte, que estão funcionando como zonas de descarga do aquífero. Isso indica que, nessa região, o SAG comporta-se como um aquífero livre, mesmo sendo recoberto na maior parte da área por espessuras variáveis de rochas vulcânicas.

Nas áreas mais planas, nos vales, a cota dos grandes rios se encontra muito próxima dos níveis estáticos, o que proporciona uma maior produtividade aos poços. Por outro lado, as áreas mais elevadas, próxima a quebras de relevo acentuadas, coincidem com os locais onde foram observadas baixas produtividades dos poços.

É possível observar que a variação do topo do SAG tende a acompanhar o relevo, enquanto que a espessura das rochas vulcânicas apresenta uma grande heterogeneidade, independente do compartimento, assumindo valores não muito elevados.

\section{CONCLUSÕES}

De uma maneira geral, o SAG na região da Escarpa da Serra Geral se apresenta de forma muito heterogênea, o que se repete também em cada um dos compartimentos. Isso levando-se em consideração as características físicas e hidrodinâmicas.

A utilização do traçado de lineamentos em diferentes escalas se mostrou uma importante ferramenta na elaboração do arcabouço estrutural, que aliadas as informações hidrodinâmicas, hidroquímicas, de produtividade e do topo do SAG, permitiu a delimitação das principais estruturas que compartimentam o SAG na região.

A cota do topo do SAG tende a acompanhar o relevo da região, apresentando cotas mais elevadas nos compartimentos CP3 e CP4, enquanto que em CP1 e CP2 verificou-se uma grande variação, desde valores negativos à positivos.

O comportamento do fluxo de água subterrânea é de seguir das áreas mais elevadas (zonas de recarga), em direção às bordas dos compartimentos, com as descargas ocorrendo tanto nas grandes drenagens encaixadas nas estruturas principais, quanto em rios menores ao longo do caminho. 0 fato de que as bordas das bacias hidrográficas estão posicionadas próximas dos altos potenciométricos permitiu supor um comportamento similar dos fluxos superficial e subterrâneo, com o SAG apresentando dessa forma uma característica de aquífero livre. 
As melhores produtividades foram encontradas nos compartimentos $\mathrm{CP} 1$ e CP2, em especial nas áreas próximas às grandes estruturas, onde se situam as principais áreas de descargas, e onde os níveis estáticos estão posicionados próximos aos níveis de base dos grandes rios, proporcionando uma maior disponibilidade de água para a explotação. Já no CP3, apesar da existência de alguns locais com valores acima de $1 \mathrm{~m} 3 / \mathrm{h} / \mathrm{m}$, em geral, as produtividades não são muito boas, porém, melhores que as encontradas em CP4, onde os valores são muito baixos.

As águas foram classificadas como bicarbonatadas cálcicas (15 poços), bicarbonatadas cálcicas ou magnesianas (25 poços), e bicarbonatadas sódicas (3 poços). 0 fato de existir, de maneira geral, pouca diferença entre as águas, independente dos compartimentos, demonstra que as variações que ocorrem se devem principalmente à influência das características locais.

Dessa forma, os resultados obtidos demonstram que, na área da Escarpa da Serra Geral, o SAG se apresenta compartimentado, e que essa compartimentação tem influência tanto na produtividade, quanto no fluxo da água subterrânea. Isso tem grande importância, pois estudos já evidenciavam a existência de uma compartimentação em escala regional, marcada por grandes compartimentos, e que agora pôde também ser observada em outras escalas, evidenciando que o SAG tem um controle estrutural associado. Estes resultados ajudam a compreender melhor a dinâmica do SAG na região, fornecendo parâmetros e informações que podem servir de subsídio para uma melhor gestão do aquífero nessa área.

\section{AGRADECIMENTOS}

Agradecimentos: Ao CNPq pelo apoio financeiro e concessão de bolsa, e a CORSAN e as empresas de perfuração pela liberação dos dados.

\section{REFERÊNCIAS}

ARAÚJO, L. M.; FRANÇA, A. B.; POTTER, P. E. Hydrogeology of the Mercosu Aquifer System in the Paraná and Chaco-Paraná Basins, South America, and Comparison with the Navajo-Nugget Aquifer System, USA. Hydrogeology Journal, v.7, p.317-336, 1999.

BETIOLLO, L. M. Caracterização Estrutural, Hidrogeológica e Hidroquímica dos Sistemas Aquíferos Guarani e Serra Geral no Nordeste do Rio Grande do Sul, Brasil. Dissertação (mestrado). Universidade Federal do Rio Grande do Sul. Instituto de Geociências. Programa de Pós-Graduação em Geociências. Porto Alegre, 116p., 2006.

DEMETRIO, J. G. A.; CORREIA, L. C.; SARAIVA, A. L. Utilização de Imagens SRTM na Confecção de Mapas Potenciométricos. In: CONGRESSO BRASILEIRO DE ÁGUAS SUBTERRÂNEAS, 14., 2006. Anais... Curitiba - PR. v. 1. p.1 20, 2006.

GIARDIN, A; FACCINI, U. F. Complexidade Hidroestratigráfica e Estrutural do Sistema Aquífero Guarani: Abordagem Metodológica Aplicada ao Exemplo da Área de Santa Maria-RS, Brasil. Águas Subterrâneas, Revista Águas Subterrâneas, v.18, n.01, p.39-54, 2004.
GIARDIN, A; FACCINI, U. F. Identificação de Células de Fluxo Local no Aquífero Botucatu: Estudo de Caso no Vale do Rio Taquari, RS, Brasil. Águas Subterrâneas. Revista Águas Subterrâneas, v. 25, n. 1, p.15-28, 2011.

HEINE, C. A. Análise da Sustentabilidade de Uso do Sistema Aquífero Guarani em Ivoti - RS. Tese (Doutorado). Programa de Pós-Graduação em Geologia - Área de Concentração em Geologia Sedimentar. São Leopoldo. UNISINOS. 173p., 2008.

HINDI, E. C. Hidroquímica e Hidrotermalismo do Sistema Aquífero Guaran no Estado do Paraná. Tese (doutorado). Programa de Pós-Graduação em Geologia. Curitiba. UFPR. 156 p., 2007.

LÖBLER, C. A.; TERRA, L. G.; SILVÉRIO DA SILVA, J. L. Dados da CPRM/SIAGAS e Imagens STRM como Base Cartográfica na Elaboração de Mapeamento em Recursos Hídricos Subterrâneos em Escala Municipal: o Caso de Nova Palma, RS. Revista Brasileira de Geografia Física, v. 07, p.513-523, 2014.

MACHADO, J. L. F. Compartimentação Espacial e Arcabouço Hidroestratigráfico do Sistema Aquífero Guarani no Rio Grande do Sul. Tese (Doutorado) Programa de Pós-Graduação em Geologia. UNISINOS. São Leopoldo-RS, 237p., 2005.

MACHADO, J. L. F.; FREITAS, M. A. Projeto Mapa Hidrogeológico do Rio Grande do Sul: Relatório Final. Porto Alegre: CPRM, 65p., CD-ROM e Mapa escala 1:750.000, 2005.

MOBUS, G. Qualigraf: programa para análise da qualidade da água. Fortaleza: FUNCEME. Disponível em: http://www.funceme.br/qualigraf. Acesso em: 20 novembro de 2016

QUEIROZ, G. L.; SALAMUNI, E.; NASCIMENTO, E. R. AzimuthFinder: Ferramenta para a Extração de Dados e Apoio na Análise Estrutural. Revista Geologia USP, Série Científica, São Paulo, v. 14, n. 1, p.69-80, 2014.

REGINATO, P. A. R. Integração de Dados para Prospecção de Aquíferos Fraturados em Trecho da Bacia Hidrográfica Taquari-Antas (RS). Tese (Doutorado) - Programa de Pós-Graduação em Engenharia de Minas, Metalúrgica e dos Materiais, Escola de Engenharia, UFRGS, Porto Alegre, 254p., 2003.

REGINATO, P. A. R.; AHLERT, S.; SCHNEIDER, V. E. Caracterização Hidroquímica do Sistema Aquífero Serra Geral na Região Nordeste do Rio Grande do Sul. Revista Águas Subterrâneas, v. 27, n. 1, p.65-78, 2013.

SANTOS, E. F.; SILVA, J. L. S.; CHAVES, A.; CAMPONOGARA, I. Vulnerabilidade à Contaminação das Águas Subterrâneas do Sistema Aquífero Serra Geral/Guarani no Município de Quaraí/RS. In: ENCONTRO NACIONAL DE PERFURADORES DE POÇOS e I SIMPÓSIO DE HIDROGEOLOGIA SUL-SUDESTE, 15., 20017. Anais... 2007.

SCHERER, C. M. S.; FACCINI, U. F.; LAVINA, E. L. Arcabouço Estratigráfico do Mesozóico da Bacia do Paraná. In: Holz, M. \& De Ros, L. F. Geologia do Rio Grande do Sul. Porto Alegre, UFRGS, p.335-354, 2000.

SOARES, A. P.; SOARES, P. C.; BETTÚ, D. F.; HOLZ, M. Compartimentação Estrutural da Bacia do Paraná: A Questão dos Lineamentos e sua Influência na Distribuição do Sistema Aquífero Guarani. São Paulo, UNESP, Geociências, v. 26, n. 4, p.297-311, 2007. 